\title{
Shared decision making in the UK: moving towards wider uptake
}

\author{
Angela Coulter ${ }^{1}$, Adrian Edwards ${ }^{2}$, Vikki Entwistle ${ }^{3}$, Graham Kramer ${ }^{4}$, Alan Nye ${ }^{5}$, Richard Thomson ${ }^{6}$, Emma
} Walker $^{7}$

1. Nuffield Department of Population Health, University of Oxford

2. Division of Population Medicine, Cardiff University

3. Health Services Research Unit, University of Aberdeen

4. Annat Bank Practice, Montrose

5. Pennine MSK Partnership, Oldham

6. Institute of Health and Society, Newcastle University, UK

7. Advancing Quality Alliance (AQuA), Salford Royal NHS Foundation Trust

\begin{abstract}
Shared decision making (SDM) is firmly on the policy agenda in the UK and a recent legal ruling has confirmed its importance. Policymakers, ethicists, professional regulators and societies, patient organisations and now the courts are committed to ensuring that SDM becomes the norm throughout the NHS, but an unfavourable economic climate makes this especially challenging. Considerable progress has been made over the last few years, with new learning from demonstration sites, various initiatives in capacity building and training, wider availability of patient decision aids, and important leadership initiatives. Enthusiasm for this way of working is growing among clinicians, patients and managers, but it could be undermined if SDM comes to be seen primarily as a means of cost control.
\end{abstract}

\section{Introduction}

There has been considerable progress towards wider implementation of shared decision making (SDM) in the UK since we last reported on this in 2011 (1). We describe these developments below, but first we will briefly outline the context in which they have been achieved.

Most UK citizens depend on the National Health Service (NHS) for almost all their healthcare needs. Funded out of taxation, the NHS covers primary care, hospital care (inpatients and outpatients), community care (including home nursing and other out-of-hospital services), and mental health care. These services are free at the point of use.

The NHS was established in 1948 and run centrally for the whole of the UK by the Department of Health in London until 1999, when responsibility for healthcare was devolved to the four nations of England, Scotland, Wales and Northern Ireland. Since then health policy has developed on somewhat different trajectories in the four nations. However, funding is still largely determined centrally and the NHS has been subject to significant financial pressures following the 2008 banking crisis and changes in government. These resource constraints, coupled with increased demand due to an ageing population, multi-morbidity and widening health inequalities, have placed the system under severe strain. However, the NHS still commands strong public support and the national health administrations have been making strenuous efforts to secure more patient-centred services and improved health outcomes while containing costs.

\section{Policy priorities}


SDM has been a policy priority for the NHS for several years. Patient organisations have been demanding a greater say in decisions about their care (2), and the NHS Constitution for England tells patients that they have the right to be involved in planning and making decisions about their health and care and to be given information and support to enable this (3). NHS England's strategic plan states that "when people do need health services, patients will gain far greater control of their own care"(4). This is mirrored in Scotland, where the Chief Medical Officer has told patients:

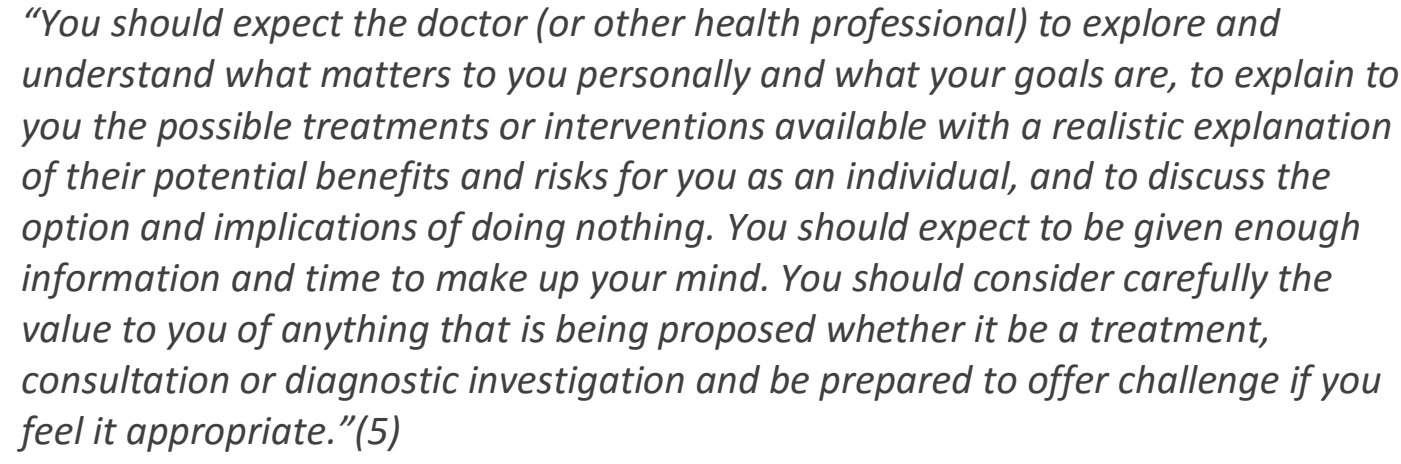

SDM is also seen as an ethical imperative by the UK's professional regulators. The General Medical Council's (GMC) statement of professional standards says that doctors should work in partnership with patients, sharing with them the information they need to make decisions about their care (6). Other regulators, including the Nursing and Midwifery Council, have espoused similar principles and these are reinforced in quality standards published by the National Institute for Health and Clinical Excellence (NICE)(7). In 2015 the government made it clear that they expected the NHS in England to become 'dramatically better at involving patients and their carers, and empowering them to manage and make decisions about their own care and treatment' (8).

Following a landmark ruling in 2015 by the Supreme Court, SDM became a legal imperative throughout the UK (9). The practical effect of this decision is that people with full mental capacity must be properly advised about their treatment options and the risks associated with each option so that they can make informed decisions when giving or withholding consent to treatment. In other words, the courts have now caught up with the policymakers, ethicists, professional and patient organisations in stating that the principles of SDM must become the norm.

The case for providing treatment, care and support that informed patients actually want, not just what professionals think they should have, is now more widely acknowledged. A growing professional movement is beginning to embrace SDM, recognising that population-based evidence, as enshrined in guidelines and frameworks, should be tempered by a more personalised approach, where clinicians and patients make decisions together, based on mutual review of the evidence but also on an understanding of the individual's personal circumstances and preferences (10).

Despite this, progress in implementing SDM across the NHS has been slow. Many health professionals still fail to comply with the requirement to inform and involve patients in all the decisions that affect them. However, there are signs that the tide is beginning to turn. Recent results from the large-scale annual national inpatient surveys for the NHS in England show an encouraging upward trend in the proportion saying they were involved in decisions about their care (Figure 1).

\section{Proof of concept}


A number of demonstration projects have taken place in various parts of the UK, exploring the feasibility of embedding SDM in routine clinical care. The Health Foundation, a London-based charity, provided funding and support for sites in the north east of England and in Wales through its MAGIC (Making Good Decisions in Collaboration) programme (http://www.health.org.uk/programmes/magic-shared-decision-making). These projects explored how to overcome the barriers to change, focusing on a multifaceted approach incorporating clinical skills development and training, patient decision aids, patient activation, clinical and organisational leadership, and support for commissioning across a range of primary and secondary care settings and specific clinical decisions (for example in benign prostate conditions, breast cancer surgery, head and neck cancer, antibiotic prescribing, cholesterol-lowering treatments, pregnancy and childbirth).

Another project, the Year of Care programme, is examining how to provide better support for people with long-term conditions by engaging them in developing personalised care and support plans (11). Demonstration sites are using a model known as the House of Care to help primary care teams adapt their services to the needs of these patients (figure 2). This focuses attention on the support and resources needed to enable personalised care planning based on SDM principles, which has been shown to improved health outcomes (12). The model has proven useful for supporting self-management in people with single conditions and with multi-morbidities. NHS England and the Royal College of General Practitioners have adopted this approach in their drive to improve services for people with long-term conditions (13).

Meanwhile, the Scottish Government has introduced a national Health Literacy Action Plan and is supporting various initiatives to ensure health service organisations and staff work in ways that make it easy for everyone to engage in SDM and more generally live well, on their own terms, with their health conditions (14). Importantly a movement of 'Realistic Medicine' is building in Scotland, a heavy focus of which is around SDM. Realistic Medicine is now a key part of Scotland's national clinical strategy (5) .

\section{Building capacity and skills}

SDM theory, skills and competencies (listening, information sharing, risk communication, options appraisal, preference diagnosis, goal setting, care planning and outcomes assessment) should be taught in medical and nursing schools and those for allied health disciplines, in post-registration training, and continuing professional development. While some UK medical schools and post-registration training schemes have made strides in this direction, there is still a long way to go (15). Various resources to support short courses, learning sets and workshops have been developed together with e-learning modules; for example, the Health Foundation has published a useful set of training resources available at http://personcentredcare.health.org.uk/resources?f\% $5 \mathrm{b0} \% 5 \mathrm{~d}=$ field area of care $\% 3 \mathrm{~A} 352$. These include advanced skills training developed as part of the MAGIC Programme that has been delivered to over 1,000 clinicians, based on a widely accepted conceptual model (16).

AQuA (the Advancing Quality Alliance), an improvement body based in north west England, has been providing SDM training for the past five years. The programme is a generic teaching and facilitation resource, underpinned by quality improvement principles, designed to provide teams with tools to understand SDM and how they can support themselves and others to develop and implement this sustainably in practice. AQUA's experience suggests that embedding SDM into mainstream practice requires organisational development techniques, challenging and changing long-held beliefs and behaviours of health professionals and patients. The AQuA approach has evolved over time to meet the changing needs of the service, but continues to use real issues that teams are grappling with to test their learning and ensure its relevance. 
There are also a number of locality-based projects to enhance health literacy, some of which integrate SDM training for clinicians. Public Health Wales has taken on dissemination of SDM principles and training, based on learning from the MAGIC project in Cardiff. This is now being taken forward by Choosing Wisely Wales (see below) with SDM training being introduced to various pacesetter sites in Wales, including selected primary care providers, the regional cancer centre and musculoskeletal services. Health Education England is also committed to extending SDM training with support from the University of Newcastle, drawing on their experience of working on the MAGIC project.

\section{Tools and measurement}

It is possible to inform and engage patients from all ages, walks of life and educational backgrounds if they are empowered by well-trained staff and, where available, provided with well-designed information materials. A centrally-funded website, NHS Choices (www.nhs.uk), that provides information about a wide range of health problems and treatments, receives more than 10 million hits each week. This includes a number of patient decision aids developed specifically for use in the UK. Freely available to all in the UK, these include 26 long- and short-form tools hosted by NHS England and validated by NICE. They were developed by NHS England's Right Care programme as part of their drive to help clinical commissioning groups (the NHS budget holders) improve quality and productivity, but over-emphasising the potential for SDM to reduce intervention rates and achieve savings risks alienating clinicians and patients.

Those using patient decision aids need to know that they can trust them, including reassurance that they comply with appropriate standards. This calls for a form of independent quality assurance or accreditation. NHS England's Information Standard operates a certification scheme for producers of patient information materials https://www.england.nhs.uk/tis/ while NICE accredits developers of clinical guidance https://www.nice.org.uk/about/what-we-do/accreditation. A combination of these approaches has been proposed as the basis of NHS certification process for patient decision aids, but as yet no funds have been made available to cover the cost of its establishment.

There is currently no consensus on how best to measure performance in respect of SDM. The national patient surveys in England include a single question about involvement in decisions which is useful for tracking trends and variations (see Figure 1), and NHS England is encouraging use of the Patient Activation Measure in a variety of projects designed to promote person-centred care (17). But a more nuanced and responsive set of indicators is likely to be needed to provide a fair assessment of how well services support people in treatment decision-making and more generally, and to inform quality improvement initiatives. This will also require funding.

\section{Coordination and leadership}

Concerns about lack of time, lack of skills, lack of resources and misapprehensions about patients' ability and desire to make appropriate choices, act as powerful disincentives to change practice. Quality improvement projects that target clinicians (attitudes, skills, adoption into clinical pathways), patients (confidence, interest, expectations and provision of decision tools), and managers (leadership, buy-in, improvement science, evaluation) are more likely to succeed than those directed at patients or professionals alone (18).

This calls for a coordinated approach to implementation, involving professional bodies, patient organisations, health information producers, and regulators. In 2015 a number of organisations came together to form an SDM Collaborative. Led by NICE, the organisation responsible for developing and promoting evidence-based guidance for health, public health and social care, the collaborative included 
representatives from NHS England, the GMC, professional bodies, patient organisations and universities from across the UK. They published a consensus statement and an action plan outlining what each of the contributors was doing to support the wider health and care system to embed shared decision making into routine practice (https://www.nice.org.uk/about/what-we-do/our-programmes/nice-guidance/niceguidelines/shared-decision-making). This included commitments to provide leadership, to develop implementation strategies, to share best practice, to provide training and guidance materials, to produce, publish and certify patient decision aids, and to promote research and knowledge translation.

Professional leadership will be especially important if SDM is to become part of mainstream clinical practice. It is therefore encouraging that the UK's Academy of Medical Royal Colleges (AoMRC) has chosen to put SDM at the centre of its Choosing Wisely campaign. Choosing Wisely began as an initiative of the American Board of Internal Medicine (ABIM) Foundation in the US. Launched in 2012, the aim was to advance a national dialogue on avoiding wasteful or unnecessary medical tests, treatments and procedures. The idea spread quickly to other countries and there are now Choosing Wisely campaigns in about 20 countries worldwide. Choosing Wisely aims to promote "better conversations" between patients and clinicians, and in the UK is predicated upon this being achieved by widespread adoption of SDM. Although the (medically-led) Choosing Wisely programme had in general not embraced SDM until recently, the AoMRC now fully intends to change that, and its recommendations are accompanied, wherever possible, by links to patient decision aids and encouragement to clinicians to share information about treatment benefits, harms and uncertainties (http://www.choosingwisely.co.uk/about-choosing-wisely-uk/). Choosing Wisely UK encourages patients to ask the following questions of clinicians:

1. Do I really need this test, treatment or procedure?

2. What are the risks or downsides?

3. What are the possible side effects?

4. Are there simpler, safer options?

5. What will happen if I do nothing?

\section{Conclusions}

Interest in SDM has grown considerably since our last overview. Commitment to the principles is strengthening, and skills and tools are being developed, but pressure on resources has worsened, making it harder for staff to deliver well on the communicative and relational practices that are integral to good SDM and harder for providers of education and support, and developers of patient decision aids, to be resourced. The policy commitment remains firm, but in this challenging climate it will be very important to keep the focus on promoting SDM because it is the best way to achieve care that people value, and not primarily a means of achieving cost control. The latter risks alienating clinicians and patients and undermining the efforts we describe above (19). Rather it is a means to ensure most effective and appropriate use of resources, based on evidence and patients' preferences (20). The fact that SDM is not only a legal requirement but simply the right way to support patients is still a message we need to broadcast.

\section{Declarations of interest}

Each of the authors has been involved in developing and delivering some of the initiatives described in this article. 


\section{References}

1. Coulter A, Edwards A, Elwyn G, Thomson R. Implementing shared decision making in the UK.

Zeitschrift fur Evidenz, Fortbildung und Qualitat im Gesundheitswesen. 2011;105(4):300-4.

2. National Voices. The narrative for co-ordinated care London: National Voices; 2013 [Available from: http://www.nationalvoices.org.uk/defining-integrated-care.

3. Department of Health. The NHS Constitution2015. Available from:

https://www.gov.uk/government/uploads/system/uploads/attachment data/file/480482/NHS Constitution WEB.pdf.

4. England N. Five year forward view. London: NHS England; 2014.

5. NHS Scotland. Realising Realistic Medicine: Chief Medical Officer's Annual Report 2015-16: The Scottish Government; 2017. Available from: http://news.gov.scot/news/realising-realistic-medicine.

6. General Medical Council. Good Medical Practice London GMC; 2013 [Available from:

http://www.gmc-uk.org/guidance/.

7. NICE. Patient experience in adult NHS services2012; (04/10/2016). Available from:

https://www.nice.org.uk/guidance/QS15/chapter/quality-statement-1-respect-for-the-patient\#qualitystatement-1-respect-for-the-patient.

8. Department of Health. The Mandate: A mandate from the Government to NHS England - April 2015 to March 20162015. Available from:

https://www.gov.uk/government/uploads/system/uploads/attachment data/file/486818/mndate-NHSE15 16.pdf.

9. Coulter A, Hopkins A, Moulton B. Montgomery v Lanarkshire Health Board: Transforming Informed Consent. Royal College of Surgeons Bulletin [Internet]. 2017; 99(1):[36-8 pp.]. Available from:

http://publishing.rcseng.ac.uk/doi/full/10.1308/rcsbull.2017.36.

10. Hoffmann TC, Montori VM, Del Mar C. The connection between evidence-based medicine and shared decision making. Jama. 2014;312(13):1295-6.

11. Coulter A, Kramer G, Warren T, Salisbury C. Building the House of Care for people with long-term conditions: the foundation of the House of Care framework. The British journal of general practice : the journal of the Royal College of General Practitioners [Internet]. 2016 Apr PMC4809714]; 66(645):[e288-90 pp.]. Available from: https://www.ncbi.nlm.nih.gov/pubmed/27033503.

12. Coulter A, Entwistle VA, Eccles A, Ryan S, Shepperd S, Perera R. Personalised care planning for adults with chronic or long-term health conditions. Cochrane Database Syst Rev [Internet]. 2015; 3:[CD010523 p.]. Available from: http://www.ncbi.nlm.nih.gov/pubmed/25733495.

13. Royal College of General Practitioners. Collaborative care and support planning: ready to be a reality2016. Available from: http://www.rcgp.org.uk/clinical-and-research/our-programmes/collaborativecare-and-support-planning.aspx.

14. NHS Scotland. Making it easy: a health literacy action plan for Scotland2014. Available from: http://www.healthliteracyplace.org.uk/media/1289/making-it-easy.pdf.

15. Foot C, Gilburt H, Dunn P, Jabbal J, Seale B, Goodrich J, et al. People in control of their own health and care: the state of involvement2014. Available from:

https://www.kingsfund.org.uk/sites/files/kf/field/field publication file/people-in-control-of-their-ownhealth-and-care-the-state-of-involvement-november-2014.pdf.

16. Elwyn G, Frosch D, Thomson R, Joseph-Williams N, Lloyd A, Kinnersley P, et al. Shared decision making: a model for clinical practice. Journal of general internal medicine. 2012;27(10):1361-7.

17. Hibbard JH, Mahoney ER, Stockard J, Tusler M. Development and testing of a short form of the patient activation measure. Health services research [Internet]. 2005 Dec PMC1361231]; 40(6 Pt 1):[1918-30 pp.]. Available from: https://www.ncbi.nlm.nih.gov/pubmed/16336556.

18. Legare F, Stacey D, Turcotte S, Cossi MJ, Kryworuchko J, Graham ID, et al. Interventions for improving the adoption of shared decision making by healthcare professionals. Cochrane Database Syst Rev [Internet]. 2014; 9:[CD006732 p.]. Available from: http://www.ncbi.nlm.nih.gov/pubmed/25222632. 
19. Schlesinger M, Grob R. Treating fast and slow: Americans understanding of and response to lowvalue care. Milbank Quarterly. 2017;95(1):70-116.

20. Mulley AT, C.;Elwyn,G. Patients' preferences matter: stop the silent misdiagnosis2012. Available from: http://www.kingsfund.org.uk/publications/patients-preferences-matter. 